\title{
BACHARELADO EM CANTO: a prática de ensino de dois professores
}

Juliana Bischoff

Recebido em 06/06/2018

Aprovado em 04/10/2018 
O presente artigo é um recorte de um projeto de iniciação científica que teve por finalidade compreender a prática de ensino de dois professores do curso de música da Universidade Estadual de Maringá, habilitação Bacharelado em Canto Lírico. Neste texto abordo questões relacionada ao ingresso do aluno de canto no curso, bem como a estrutura do currículo e a dinâmica das aulas na perspectiva dos entrevistados. Os dados revelam o envolvimento dos professores com o curso e os princípios que eles usam em suas práticas pedagógicas que não estão formalizados no projeto pedagógico do curso.

Palavras-chave: Canto, Ensino Superior, Bacharelado

\section{INTRODUÇÃO}

Este texto discute a atuação de professores de canto no ensino superior. Trata-se de um recorte dos resultados de um projeto de iniciação científica (PIC), que teve como foco a prática pedagógica de dois professores do bacharelado em canto do curso de música da Universidade Estadual de Maringá (UEM).

A pesquisa investigou os procedimentos metodológicos dos professores, buscando compreender os encaminhamentos pedagógico-musicais neste nível de ensino, bemcomo discutindo temas relacionados, tais como afinação/desafinação, dom em música, relação professor/aluno, entre outros que emergiram das entrevistas. Neste texto, em específico, tratarei sobre questões relacionadas ao vestibular, aluno iniciante e estrutura das aulas, na perspectiva dos professores entrevistados.

A preocupação com a atuação no ensino superior tem sido tema de pesquisas na área da música, dentre eles as pesquisas de Mateiro (2009), Freire (2010), Louro (2004, 2015), Santos (2015), Silva (2016), Bischoff (2017), Queiroz (2017), entre outros. Estas apontam para a importância de reflexões acerca dos aspectos pedagógicos musicais no ambiente universitário.

Esta pesquisa, de caráter qualitativo, teve como método investigativo o estudo de caso e como técnica de coleta de 
dados a entrevista semiestruturadas e análise de documentos relativos ao curso (Projeto Político Pedagógico e programas de disciplinas).

Para coleta de dados foram entrevistados os professores do bacharelado. Abordei questões referentes ao ensino de canto na universidade, estratégias metodológicas e didáticas, formação profissional dos professores, e questões específicas do bacharelado em canto da UEM.

As entrevistas foram feitas com a Profa. Michele Coelho e Prof. Dr. John Kennedy Pereira de Castro. A profa. Michele Coelho formada pela EMBAP, foi professora temporária e atuou por quatro anos no bacharelado em canto da UEM. Além de professora de canto, ela atua na área da performance. Atualmente está cursando mestrado em performance musical em Veneza, na Itália.

Castro, que é professor efetivo da UEM desde 2004, também tem formação em bacharelado em canto pela EMBAP (Escola de Música e Belas Artes do Paraná), mestrado pela USP (Universidade de São Paulo), na área de canto/canção brasileira, e doutorado pela Universidade Federal de Minas Gerais, também na área de canto/canção brasileira.

O ensino superior de canto na Universidade Estadual de Maringá teve início em 2002, e desde então tem se consolidado em sua região, acompanhando um momento histórico de ampliação da oferta de cursos superior em no Brasil:

No Brasil, a ampliação da oferta da educação superior, consolidada principalmente a partir da década de 2000, teve grande impacto na área de música, considerando que, nesse período, houve uma significativa expansão dos cursos de graduação da área [...]A partir dos anos 2000, como resultado do novo cenário estabelecido para a educação superior, os cursos de graduação e pósgraduação em música cresceram extraordinariamente. (QUEIROZ, 2017, p. 135)

Segundo o projeto político pedagógico (PPP) do curso de música da UEM, da formação do bacharel, resultará: o intérprete que atuará como solista, em orquestras, conjuntos populares, religiosos ou de câmara. O campo de trabalho do músico profissional abrange órgãos públicos e particulares, 
rádio, TVs, teatros, instituições religiosas, mercado publicitário, entre outros. O bacharel em canto poderá atuar também na área da pesquisa musical (PPP, 2002).

Podemos observar que área de atuação do bacharelado em canto, segundo o PPP é ampla, contudo, a organização do currículo, bem como seu impacto na formação do bacharel carece de pesquisas especificas para a validação de que as intenções postas no documento de fato se efetivam. O curso possui autorização para ofertar dez vagas anuais.

\section{PROVA DE APTIDÃO ESPECÍFICA NO VESTIBULAR}

Para ser admitido no curso, o candidato deverá prestar exame de aptidão específica (artigo 27, parágrafo $2^{\circ}$, Res. 079/2004 - CEP). Essa Prova é popularmente conhecida como "prévia", pois acontece antes do vestibular geral da universidade.

O candidato é submetido a uma prova de percepção musical, de conhecimentos gerais de música, em um dia, e no outro dia a prova prática de canto. Se for admitido o candidato conquista o direito a prestar o vestibular de música, que geralmente acontece numa média de dois meses após essa prova. Caso não consiga a pontuação mínima na prova prévia, não sendo admitido, o candidato tem o direito a escolher outro curso para prestar o vestibular.

Nesta prova, segundo o PPP, é avaliado se o candidato tem conhecimentos equivalentes ao de nível técnico em música (PPP, 2002).

Segundo o site do curso de música da UEM, o programa da prova contempla conhecimentos em percepção musical e conhecimentos gerais em música, que compreende na leitura rítmica e melódica, além de aspectos específicos da teoria básica da música:

Leitura à primeira vista de ritmo a uma voz; leitura à primeira vista de exercício de entonação melódica em tonalidade maior ou menor; ditado de ritmo a uma voz; ditado melódico a uma voz em tonalidade maior ou menor. Reconhecimento de tipos de acordes (tríades maiores, menores, aumentadas e diminutas). [...] 


\begin{abstract}
Elementos de grafia musical e teoria do sistema tonal: intervalos (melódicos e harmônicos);escalas maiores e menores (natural, melódica e harmônica);classificação de acordes (tríades maiores, menores, aumentadas e diminutas); campo harmônico maior e menor (natural, melódica e harmônica); compassos; armadura de clave; claves (de dó, de sol e de fá). (Prova De Percepção e Conhecimentos Gerais De Música) ${ }^{1}$
\end{abstract}

Esses conteúdos relacionados a conhecimentos de teoria e percepção musical, integram o currículo do curso em disciplinas como: contraponto, harmonia, percepção, entre outras. Estas disciplinas seguem um padrão como em conservatórios:

[...] são estratégias de organização de saberes com forte influência do modelo disciplinar dos conservatórios europeus que se fortaleceram a partir do século XVIII, tendo como base, sobretudo, as definições de instituições como o Conservatório de Viena e o Conservatório de Paris[...]. Portanto, esses conhecimentos fazem parte de um leque de disciplinas e formas de pensar o currículo em música que subsidiou a criação e a consolidação de escolas de música em diferentes contextos, sobretudo nos países colonizados pela Europa, como é o caso do Brasil (QUEIROZ, 2017, p. 153).

Do que diz respeito ao bacharelado em canto e a prova de habilidades específicas ou popularmente conhecida como a parte prática da prova "previa" de música é exigido:

Para todas as provas práticas, o candidato deverá fornecer para a banca examinadora cópia das peças executadas e poderá optar pela execução com acompanhamento instrumental, sendo de sua responsabilidade trazer o instrumento, exceto para o piano que estará à disposição no local de realização da prova; as obras apresentadas serão de livre escolha do candidato (com exceção de leitura à primeira vista).[...]

\title{
Bacharelado em Canto
}

Uma ária ou canção italiana dos séculos XVII ou XVIII.

disponível em: http://www.uem.br/index.php?option=com_content\&view=category\&layout=blog\&id=16\&ltemid=134, acessado em: 30/06/2017). 
Uma canção francesa do período barroco ou clássico. Uma canção alemã (Lied), à escolha do candidato, de um dos seguintes autores: Mozart, Schubert, Schumman, Beethoven, Brahms.

Uma peça de autor brasileiro, dentre os autores sugeridos: Waldemar Henrique, Oswald de Souza, Lorenzo Fernandes, Alberto Nepomuceno, Claudio Santoro, José E. Gramani, Barrozo Netto, A. Bocchino, Jayme Ovalle, A. Carlos Gomes, Alberto Costa, Arnaldo Rebello, Marcello Tupynambá, Guerra Peixe, Villa-Lobos. (Prova Prática De Instrumento/Canto, Regência E Composição) ${ }^{2}$

\section{A "PREVIA"NA VISÃO DOS PROFESSORES}

Castro, professor de canto, demonstra uma preocupação na escolha do repertório da prova específica de canto. Ele diz que ao formular a prova do vestibular e o programa do curso, foi considerada a realidade do aluno que presta o vestibular, onde muitas vezes é o primeiro contato que tem com o repertório lírico: “[...] o nosso aluno entra para fazer essa experiência com o canto lírico de primeira mão na graduação [...] Quando resolvemos reformular o curso, foi pensando no perfil do nosso aluno pensando na nossa região, essa foi a ideia" (CASTRO, 2017).

Mesmo tendo essa preocupação em adequar a prova do vestibular, assim como o curso de canto lírico, e embora exista um programa de canto que é cobrado nas provas do vestibular, profa. Coelho afirma que o mais importante no momento da prova é verificar que o aluno possui uma "voz" para o canto. Em suas palavras: "às vezes a pessoa não tem nem conhecimento do mundo do canto, e nem conhecimento técnico, mas a voz está lá. Se eu vejo a matéria prima eu aceito esse aluno" (Profa Coelho).

Na fala de Coelho percebe-se que o domínio da voz e os aspectos de técnica vocal não são determinantes na aprovação do candidato ao ingresso no curso da UEM, avalia e busca sentir se o candidato possui uma pré-disposição vocal para o canto lírico. Ou seja, como é "o material vocal" do aluno.

disponível em: http://www.uem.br/index.php?option=com_content\&view=category\&layout=blog\&id=16\&ltemid=134, acessado em: 30/06/2017). 
Ela ainda relata sobre sua experiência pessoal no início de seu estudo de canto também tinha pouco conhecimento de canto lírico. Apesar de Coelho não ter sido aluna da UEM e de ter feito sua graduação em Curitiba, Belas Artes, também foi admitida no vestibular de música, mesmo tendo pouco conhecimento sobre canto lírico, porém, tinha um "material vocal" considerado satisfatório: "eu mesma quando entrei na faculdade não tinha a menor ideia, tinha visto uma ou duas óperas. Não sabia quase nada, e tudo que eu soube foi porque eu mesma sentei lá na frente do Youtube e pesquisei" (Profa Coelho).

Podemos notar a preocupação dos professores com o contexto do aluno que busca fazer uma formação superior em canto lírico na UEM. Fica claro que para a região de Maringá o canto lírico ainda está sendo difundido e a maior parte dos alunos que chegam à graduação não teve a oportunidade de vivenciar o canto lírico, sendo o curso superior (mesmo sendo um curso superior), muitas vezes, sua primeira oportunidade. Isso, de acordo com prof. Castro é uma questão da "cultura geral" do aluno:

Não é só o canto, a gente lida com a cultura e os nossos alunos vêm com pouca formação de cultura geral, de leitura musical e pouca formação da nossa cultura artística. O canto está envolvido numa cultura geral e se o acadêmico não tem esses conhecimentos básicos, com certeza, ele terá algum tipo de dificuldade em seu desenvolvimento durante a graduação (prof. Castro).

Apesar de no PPP do curso de música estar descrito que o aluno que entra na instituição é cobrado um nível técnico (PPP, 2002), não é ofertado em Maringá e região nenhum curso técnico em canto. Perante essa realidade podemos observar que há um currículo oculto (Silva et al, 1996), onde os professores buscam estratégias de flexibilização das exigências tanto na prova de admissão do aluno, quanto dos conteúdos que são ministrados nas disciplinas de canto. Eles buscam, por questões pedagógicas e humanas, atender a necessidade do aluno dentro do contexto social de uma região ainda carente de ofertas nesta área. Portanto a prática se difere dos documentos que orientam o curso. 


\section{ESTRUTURA CURRICULAR EM PRÁTICA}

$\mathrm{Na}$ estrutura curricular do curso de canto, além das disciplinas teóricas, há as específicas direcionadas ao canto. Dentre elas: Canto I, II, III e IV, Prática de Repertório I, II, III, e IV, em ambas o acadêmico tem aulas individuais. Na primeira a aula é ministrada pelo professor de canto/técnica vocal, a duração da aula é de cinquenta minutos. A segunda, Prática de Repertório, fica na responsabilidade do professor que é pianista correpetidor, onde é feita orientações acerca dos estilos e interpretação das peças musicais, aula com duração de cinquenta minutos.

Castro relata a dificuldade que encontrou na universidade em relação as aulas individuais:

É uma pressão muito grande: "Você dá aula só para um aluno na sala de aula". As outras áreas do conhecimento que dão aula para cinquenta, precisão entender que, considerando características próprias, em qualquer lugar do mundo a aula de canto, cursos de bacharelado, é individual e atendem uma formação específica e com especificidades próprias do cantor intérprete e artista. (prof. Castro)

Castro justifica a importância e a dificuldade que teve para implementar a disciplina de prática de repertório, que é ministrada pelo pianista correpetidor. Além da dificuldade dentro da universidade, ele também encontrou dificuldade dentro do próprio departamento de música:

[...] tinha uma resistência grande em não aceitar o perfil do pianista correpetidor como docente, mas como técnico. Pode ver que, na grade do curso de bacharelado em canto, o pianista correpetidor é professor e não técnico... Uma conquista! É a única habilitação em que temos a disciplina 'Prática de Repertório' sob a orientação de um pianista correpetidor. (Prof. Castro)

Desde sua criação houve mudanças no currículo do curso, onde foram criadas e extintas disciplinas, também feito adaptação em ementas de disciplinas, sempre buscando a melhoria, e atender a realidade local, para assim proporcionar a aluno um aprendizado eficiente e de qualidade.

Partindo desses pressupostos, realidade local, aluno e eficácia do ensino o prof. Castro, afirma: 
[...] em nossa realidade local não temos um corpo de profissionais cantores e nem produção lírica vinculada ao teatro para assistir uma ópera ou assistir um concerto de música antiga por exemplo. A realidade da nossa região é outra. [...] O que temos é uma ferramenta maravilhosa de mídia que é a internet que nos possibilita ouvir excelentes performances e intérpretes e, sempre com a mediação do professor, dar direção ao aprendizado do estudante de canto. Primeiro ano de curso se aconselha muito ouvir e interagir com as mais variadas expressões estéticas do canto lírico, sempre mediadas pelo professor, à construção de uma dinâmica de estudo e orientação ao acadêmico iniciante. (Prof. Castro)

Segundo o prof. Castro, o aluno tem como uma das principais referências musicais, a internet. Por essa fala podemos perceber que a internet é uma grande ferramenta de ensino. Porém ele afirma que é necessária a direção do professor, pois o aluno iniciante ainda não tem autonomia para discernir questões da voz cantada, muitas vezes desenvolvendo um canto com muitos vícios:

Muito alunos quando entram na graduação tem, ainda inocentes e com pouca experiência, a prática de imitarem as interpretações a partir do YouTube. Eles ouvem, por exemplo, o Jonas Kaufman cantando, um grande intérprete internacional, contudo incorrem no erro de imitar sem ter, ainda, a consciência e condicionamento técnico vocal e corporal à realização de uma performance de alta exigência técnico musical. Muitas vezes tal prática leva o/a jovem estudante de canto a uma caricatura e, também, adquirir problemas vocais por conta das indevidas compensações incorporadas na tentativa de cantar repertórios indevidos ao seu atual estágio de estudo. Corrigir as tensões adquiridas pelo estudo errado passa a ser um problema muito mais trabalhoso de se resolver do que construir uma voz saudável. Assim que eu penso (Prof. Castro)

Castro defende que além da orientação com o professor correpetidor, o ideal seria mais uma aula de canto. Dessa forma seriam três aulas individuais por semana, duas voltadas para a técnica vocal, e uma para a prática de repertório. Como o aluno que chega à graduação na UEM é iniciante, muitas vezes tendo pouco 
contato com o canto lírico. Por meio dessas aulas, esse aluno teria uma orientação bem direcionada, podendo assim construir de forma mais sólida a base do seu aprendizado.

Na minha opinião, o primeiro ano precisaria ter pelo menos duas horas aulas com o professor de canto. Eu defendo, para o aluno do primeiro ano, duas aulas semanais, sendo uma mais no início da semana e outra no final. Após verificar quais exercícios vocais, decorrido um ciclo de aulas dadas, o aluno já tenha domínio e já consiga manipular por si mesmo, desde que o resultado seja coerente com o que a gente espera, então, passo a orientar o estudo diário individual e autônomo. Lembro que é um perigo o acadêmico iniciante estar estudando sem ter a noção bem fundamentada às percepções de sua voz pois ele pode correr o risco de começar a criar hábitos errados e, também, adquirir compensações danosas... Isso é muito delicado nesse processo inicial do estudo do canto. Nesse processo inicial se faz necessário que que o professor, enquanto mentor, possa andar lado a lado com o aluno a fim de monitorá-lo na construção de um fundamento técnico interpretativo orgânico e, acima de tudo, vocalmente (Prof. Castro)

Porém, há muita resistência da universidade para viabilizar essa segunda aula de canto.

Sigo defendendo, com relação a aula de canto, pelo menos duas vezes por semana. No Brasil nós temos um perfil de ingresso que é irreal quanto a exigência de conhecimento musico vocal prévio aos cursos de graduação em música. Temos a seguinte constatação: o curso é bacharelado, mas o acadêmico, infelizmente, só conta com uma única aula semana da principal disciplina de sua formação que é a aula de canto (técnica e interpretação). Essa foi e segue sendo minha luta na universidade, que possamos implantar as duas aulas semanais de canto. Atualmente o bacharel em canto só tem uma hora/aula de trabalho técnico vocal. O que que fizemos, como estratégia, foi criar disciplinas práticas de grupos vocais, otimizando assim maior ênfase e desenvolvimento do aluno cantor (CASTRO, 2017). Além dessas disciplinas, onde o aluno tem um atendimento individual, há outras direcionadas ao 
canto, porém em uma abordagem coletiva: Estúdio Ópera, Prática de Conjuntos Vocais I e II, Dicção Lírica I e II, Coro I e II, e Prosódia. Quanto às disciplinas em conjunto Castro diz:

Talvez mudemos o estúdio ópera para laboratório de canto, onde possamos realizar, não só ópera, mas outros projetos de distintos gêneros vocais. Dessa forma poderemos ter, a cada ano, um projeto distinto como: projeto com cena de modinha, outro com serestas brasileiras, ou ainda outro com ópera (estrangeira ou brasileira) ou musicais. Eu tenho pensado muito em transformar o estúdio ópera em laboratório, porque - laboratório de canto me permitirá planejar vários distintos projetos além da ópera. O intuito de criar essas disciplinas foi (grupos vocais, ópera estúdio e o máster class) para dar mais espaço à prática do canto. (Prof. Castro).

Ainda sobre aulas coletivas, ele comenta a respeito do laboratório de canto e do máster class:

O laboratório de canto e máster class são disciplinas abertas ao público onde o aluno de canto já se expõe publicamente e, principalmente por ser o bacharelado de enfoque artístico, inevitavelmente, em recitais e concertos numa relação de intérprete e público (audiência). Então, o máster class cumpre essa função, ele tem uma intervenção pedagógica, mas também tem uma exposição aberta ao público. Dessa forma, o aluno começa a enfrentar a realidade de ser um cantor. Ele também começar a construir uma realidade de interação com os seus pares, ouvindo e participando nas colocações e tendo assim os mais diferentes pontos de vista como feedback. Como falei antes, a dimensão da escuta é muito importante contribui na construção do sentido. Esse foi esse o objetivo quando a criamos tais disciplinas. (Prof. Castro).

Podemos observar que há uma preocupação de adequar a estrutura curricular para a realidade do contexto cultural da região de Maringá. Há também um cuidado em atender as necessidades do aluno, e proporcionar um ensino, onde tenha um equilíbrio entre o estudo da técnica e a prática do canto voltado para a performance, graças a existência de um currículo oculto. 


\section{ESTRUTURA DAS AULAS}

O bacharelado em canto da UEM é um curso relativamente jovem, existe há 16 anos. Ao longo desses anos vem sendo feitas mudanças para a melhoria do curso. Quando se pensa em estrutura de uma aula de canto em um curso superior, podemos afirmar que é essencial levar em consideração o aluno que ingressa nesta instituição.

Partindo desses princípios, também perguntei para os professores entrevistados como eles estruturavam suas aulas, e como seria uma primeira aula pra o aluno que acabou de ingressar no bacharelado em canto da UEM.

A prof. Coelho afirma que é muito importante a conversa com o aluno, é importante investigar a sensações, como esse aluno se relaciona com a própria voz:

É importante observar se existe algum tipo de indicio de patologia, isso é uma coisa que investigo na primeira aula. Faço algumas perguntas: quais os hábitos, se bebem, fumam, comem bem, tem refluxo. Faço um pequeno questionário da vida da pessoa, dos hábitos dela, tudo isso influencia na voz. [...] Essas coisas você precisa verificar de primeira, se a pessoa sente alguma coisa estranha. Por isso eu estou sempre perguntando: como você se sente, como você sentiu isso, o timbre as passagens na questão da classificação é a primeira coisa que você tem que observar, na minha opinião é como eu faço assim. (Prof. Castro)

$\mathrm{Na}$ mesma direção o prof. Castro também ressalta a importância da conversa para o processo de ensino e aprendizagem. Porém ele prioriza conhecer a história do aluno primeiramente, antes de conhecer a voz. Por meio dessa conversa, com troca de experiências, busca criar uma afinidade, uma parceria com o aluno:

Eu vou primeiro conhecer quem ele e conhecer seu percurso ao estudo do canto. Ele até pode cantar no primeiro encontro, mas não estou tão preocupado com o canto. Eu vou escutar a fala dele onde eu já tenho a possibilidade de perceber muitas coisas com relação a colocação vocal, percepção, entendimento musical, literatura do canto, etc... Eu defendo que se faz necessário criar uma afinidade entre o orientador e 
orientando, ter uma relação de empatia e diálogo franco e direto. Nesse processo pedagógico a gente tem que falar muito em parceria. Não é só o professor, têm que ser os dois pois não adianta eu te orientar e você não fazer a sua parte com relação ao estudo individual e diário. [...] o aluno vai realizar o processo eu, mentor, vou dar as diretrizes e conduzir ao desenvolvimento do aluno. Numa conversa inicial o aluno se apresenta e fala um pouco de sua trajetória e ideais. (Prof. Castro)

No que diz respeito a relação professor e aluno e o impacto do desenvolvimento do aprendizado do canto Sunderberg (2015) afirma:

Os efeitos do estado de humor sobre a voz provavelmente explicam também a importância de uma relação amigável e descontraída entre professor e o estudante de canto para a obtenção de bons resultados durante o processo de ensino/aprendizado vocal. Em contrapartida, desavenças pessoais ou problemas de relacionamento que possam gerar uma atmosfera tensa durante a situação de aprendizado provavelmente dificultarão o processo de desenvolvimento de uma produção vocal livre de tensões desnecessárias (SUNDBERG, 2015, p.216).

Após esse primeiro contato, essa conversa, vem uma abordagem mais direta relacionada a técnica vocal, levando em consideração a história do aluno. Em um segundo momento a prof. Coelho fala da importância da estruturação da aula:

A aula depende dessa estruturação. O professor não pode começar sua aula com um vocalize de oitava. Primeiro vai fazer um bocca chiusa, pra dar uma aquecida na musculatura pra não machucar o aluno, depois vai começar com exercícios menores de uma extensão menor, no máximo até uma quinta. Em sequência vai trabalhando aspectos específicos do canto como um exercício de articulação pra acordar a musculatura do rosto da pessoa, depois um exercício de ressonância pra ela sentir um ponto bem alto, só depois desse preparo eu trabalho os vocalizes pesados, os vocalizes que tem mais extensão, só no final da aula. Tudo tem que ser esquematizado, com muito cuidado para não machucar o aluno. (Profa Coelho). 
Nesse aspecto relacionados a técnica vocal, o prof. Castro tem outra abordagem. Ele, a princípio, ressalta a importância de se desenvolver uma técnica de respiração consciente voltada para o canto. Ele fundamenta a sua aula no conhecimento da respiração e como ela interfere no processo de fonação, na voz cantada.

O trabalho com a respiração se realiza sempre antes do trabalho de emissão, explicando a importância da respiração consciente e correta à sustentação de notas e frases musicais. Começar a trabalhar pequenas frases, intervalos pequenos, para que ele se consciente e conduza o cantar sobre fluxo de ar sendo que que na fala é involuntário, mas no canto não. [...] a respiração, sempre a respiração, é a base do canto. Aplico os exercícios e ele respira e logo após começa a emitir, conduzindo e dominando consciente e gradualmente o fluxo de ar à emissão sonora cantada. [...] E sempre dar muita atenção as sensações de como é que ele está emitindo o som. O professor pode intervir, exemplo: opa essa frase ficou ótima, ele fez a segunda nota, ficou ótimo, eu não senti nenhum aperto. (Prof. Castro)

E partindo da respiração como fundamento do ensino do canto, em específico para alunos iniciante. Prof. Castro ressalta a importância de se conhecer o aluno, do professor estar bem presente nesse início de estudo e conduzir o mesmo para um autoconhecimento, ou seja, de conhecer como funciona o próprio corpo em função do processo da fonação, de como essa voz é produzida.

Sim, no primeiro semestre eu gosto de ir além do trabalho técnico e respiratório pois penso que estimular uma interação dos mecanismos e princípios fisiológicos e musicais no canto se faz necessário desde o início do estudo do canto. É fundamental, nesses primeiros seis meses de contato professor versus aluno, construir uma postura de estima e confiança. É desse primeiro semestre que depende todo processo que o aluno vai deslanchar no resto do curso e se ele levar a sério, inevitavelmente, muito bem-sucedido será em seu processo de aprendizagem. (Prof. Castro)

Podemos notar que os professores têm uma preocupação com o planejamento e estrutura das aulas. Porém eles afirmam que apesar de ter esse planejamento, e para que aula siga da 
forma que foi planeja, depende muito do aluno, de como ele se apresenta para aula.

O aluno chega com a voz cansada, não dormiu bem, está com algum problema emocional, ou seja, com o desempenho da voz prejudicado. Nesses casos, o planejamento não vai funcionar. Então ao pensar em uma aula de canto, precisamos levar tudo isso em consideração. [...] Tudo depende de como o aluno está, por isso varia muito não tem uma formula. Varia de acordo com a voz do aluno, como ela vai estar no dia. Partindo de como a voz do aluno se apresenta, posso definir o que trabalhar se vou direcionar para um trabalho mais técnico ou para o repertório. (profa Coelho)

Segundo prof. Castro:

É muito particular. Eu não vou te dizer que eu vou ter o mesmo procedimento e não é $100 \%$ igual, pois cada um é cada um. Chega uma pessoa com uma realidade músico vocal iniciada e, às vezes, já desenvolvida, podendo já, na terceira ou quarta aula, começar com processo de cantar. O outro chega totalmente iniciante e, então, eu não posso exigir o mesmo resultado. Tenho que saber o estágio vocal, emocional que ele se encontra e verificar o conhecimento que ele tem com relação à música e, em especial, ao canto. (Prof. Castro)

A prof. Coelho destaca a importância de flexibilizar o planejamento conforme as necessidades do aluno. Ela fala das estratégias que utiliza, para assim buscar também saúde vocal aliado a um resultado musical:

Se for passar o repertório, tenho o cuidado para não levar o aluno ao extremo, no momento do aquecimento e cansar a voz, tenho que pensar que ainda vai ter que passar o repertório. Se não tiver a intenção de passar o repertório, dou uma aula de técnica mais profunda que exige mais do aluno. (Profa Coelho)

Além das questões específicas de técnica vocal, também há uma preocupação em adequar o repertório conforme a realidade do aluno.

Eu costumo fazer com os alunos um repertório que seja adequado a voz de cada um, dentro daquilo que está proposto lá no programa. Porem tem vozes muito jovens que não dá pra cumprir o programa, ai a gente adapta o 
programa. [...] Por exemplo: se entra um contratenor no curso de música da UEM, que repertório que essa pessoa vai fazer? Ai vai ter lá, ária de ópera italiana do período romântico, o que um contratenor vai fazer. Então tem que ter essa flexibilidade. (Profa Coelho)

O prof. Castro afirma que o bacharelado em canto prioriza um número menor de peças para assim focar na qualidade do repertório que será desenvolvido pelo aluno: “Temos tentado adequar o repertório com uma quantidade menor de peças para que os alunos possam ter mais tempo de maturação e, também, para que o egresso possa sair com uma experiência de refinamento maior, adquirida ao longo do curso" (prof. Castro).

Ele ainda fala que além de estudo de técnica vocal e repertório, existe um estudo teórico, onde o aluno precisa conhecer o contexto histórico o cultural das peças que estiver interpretando. E também questões relacionadas à anatomia e fisiologia do aparelho fonador.

Posteriormente o aluno pode estudar e se dedicar mais a fisiologia, estudar bastante o repertório. [...] porque é uma questão musical, tem outros aspectos que ele precisa estudar além da técnica vocal. Nesse início ele pode ler a literatura, começar a ter elementos de estilo, exemplo: "ah eu estou estudando uma peça de Schubert". Quem foi Schubert? Que período? Então situar-se no contexto da obra em estudo. (Prof. Castro)

Podemos notar que o aluno de canto tem particularidades que requerem um amplo estudo que envolve áreas diversas do conhecimento, tais como: história da arte, literatura, idiomas, anatomia e fisiologia do corpo humano, além de todo o conhecimento musical. Portanto o estudo do canto lírico pode ser considerado uma tarefa bem complexa, e podemos compreender o porquê da preocupação dos professores em adequar toda a fundamentação do ensino, por meio de um currículo oculto. Creio que dessa forma, o aluno pode interagir mais com esses conteúdos, criando assim uma identidade. Em específico o aluno da UEM, como pode observar nas falas dos professores, geralmente é um aluno iniciante, que pouco contato teve com o universo da música erudita e do canto lírico.

O prof. Castro integra o quadro de docente do curso de música da UEM desde o terceiro ano de sua criação. Ele vem 
sendo o principal responsável pela estruturação da habilitação Bacharelado em Canto. Podemos observar em suas falas, como ele tem cuidado em buscar um equilibro entre o ensino e aprendizado e a necessidade e demanda local.

Maringá é conhecida como cidade canção, tendo uma tradição forte com o canto, principalmente o canto coral. Porém o canto lírico vem sendo ensinado de forma mais estruturada, desde que foi criado o curso de música no ano de 2002. Portanto como já foi dito nesta pesquisa, ainda está sendo difundida a prática do canto lírico.

Segundo o prof. Castro

Então, a princípio, na formação do nosso aluno, olhando a nossa realidade regional e econômica, não a de Curitiba e São Paulo que já tem uma história de dezenas de ano de tradição, notamos que aqui temos muito pouco tempo, quinze anos de curso de música de graduação. [...] o nosso aluno entra para ter essa experiência com o canto lírico, de primeira, mão na graduação. Então não adianta exigir um repertório de dezesseis peças no primeiro ano, como fizemos no início do curso. No início foi muito pesado e sofrido para os alunos e para nós também. Quando resolvemos reformular, foi pensando no perfil do nosso aluno local (Prof. Castro).

Podemos observar que a principal motivação para as mudanças no modelo pedagógico do bacharelado em canto da UEM, é a o contexto cultural que está inserido o aluno que busca o curso.

\section{CONSIDERAÇÕES FINAIS}

Apesar do Bacharelado em Canto da UEM ser relativamente novo, podemos observar que há um cuidado e preocupação em adequar as disciplinas a necessidades e demanda regional. Sem perder as características do ensino do canto lírico, por meio de um currículo oculto, buscando um equilíbrio e diálogo entre a demanda local e a prática de ensino desta arte.

Mesmo não sendo da área da educação, podemos observar que os professores demonstram cuidado com planejamento das aulas, e com o contexto do aluno e suas demandas, buscando 
um equilíbrio entre o ensino e aprendizado musical em virtude da performance.

Pelas falas dos professores, podemos observar que parte dos alunos que ingressam no bacharelado em canto da UEM está no início do estudo, tendo pouco conhecimento e contato com o canto lírico. Também podemos observar que os professores são bem sensíveis a essa realidade, e que buscam estratégias para proporcionar um maior contato do aluno com a prática do canto lírico de forma mais consciente.

Assim como os outros cursos de música do Brasil, e apesar de a última reformulação ter acontecido em 2013, o bacharelado de em canto da UEM segue um modelo conservatorial (PEREIRA, 2014) com traços de colonialidade (QUEIROZ, 2017), isso é presente especialmente nas disciplinas gerais, como contraponto, harmonia e outras.

Neste artigo busquei expor, por meio das falas dos professores, como é pensada a forma de ensino em um curso superior voltado para a performance. Creio a literatura carece de mais estudos nesta direção, organizando e analisando dados empíricos que permitem reflexões sobre da atuação docente e o crescimento da área da música como ciência. 


\section{REFERÊNCIAS}

BISCHOFF, Juliana. O Perfil dos professores de canto no ensino superior de música da UEM.: um estudo em andamento. In: XXIII Congresso Nacional da Associação Brasileira de Educação Musical Diversidade humana, responsabilidade social e currículos: interações na educação musical. Manaus, 16 a 20 de outubro de 2017

FREIRE, Vanda Bellard. Música e Sociedade: uma perspectiva histórica e uma reflexão aplicada ao ensino superior de Música $2^{\circ}$. ed. rev. e ampl. Florianópolis : Associação Brasileira de Educação Musical, 2010.

LOURO, Ana Lucia de M. e L. Ser docente universitário-professor de música: dialogando sobre identidades profissionais com professores de instrumentos. Tese (Doutorado em Educação) - Programa de Pós-Graduação em Educação, Faculdade de Educação. Universidade Federal do Rio Grande do Sul, Porto Alegre, RS. 2004.

MATEIRO, Teresa. Uma análise de projetos pedagógicos de licenciatura em música. Revista da ABEM, Porto Alegre, V. 22, p. 5766, 2009.

PEREIRA, Marcus Vinícius Medeiros. Licenciatura em música e habitus conservatorial: analisando o currículo. REVISTA DA ABEM. Londrina, v.22, n.32, p. 90-103. Jan.jun 2014.

PROJETO POLÍTICO PEDAGÓGICO. Resolução No 170/2015CI / CCH. Departamento de Música da Universidade Estadual de Maringá. 2012.

QUEIROZ, Luis Ricardo Silva. Traços de colonialidade na educação superior em música do Brasil: análises a partir de uma trajetória de epistemicídios musicais e exclusões. Revista da ABEM. Londrina, v.25, n.39, p.132-159. Jul.dez. 2017.

SANTOS, Lucíola F. dos. O processo de formação do cantor lírico no ensino superior: discussão dos conceitos de Formação, Competências e Conteúdos e suas articulações no ensino e aprendizagem do canto lírico. Trabalho apresentado no XXII Congresso Anual da Associação Brasileira de Educação Musical - 2015. Disponivel em: http://abemeducacaomusical.com.br/conferencias/index.php/ xxiicongresso/xxiicongresso/sch edConf/presentations. 
SILVA, Bruna Williena. Flauteando com os licenciandos do curso de Música - PARFOR: Uma experiência em formação de professores. In: XVII encontro regional sul da ABEM. Curitiba: Associação Brasileira de Educação Musical, 2016.

SILVA, Elcio O. MOREIRA, Mariano. GRANADO Neiva Ignês. O contrato didático e o currículo oculto: um duplo olhar sobre o fazer pedagógico. Zetetike, Campinas SP, v.4 n.6 p.9 - 23 julho/dezembro de 1996.

SUNDBERG, J. Ciência da Voz: Fatos sobre a voz na Fala e no Canto. Tradução e revisão. Gláucia Laís Salomão. - São Paulo: Editora da Universidade de São Paulo, 2015. 